\title{
Autonômico no Exercício Físico em Modelo Genético de Insuficiência Cardíaca
}

\section{Tachycardic Response and Autonomic Control in Physical Exercise in Genetic Model of Cardiac Insufficiency}

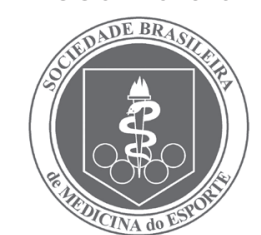

Artigo Original

\author{
Telma F. Cunha \\ Thaís A. Saito \\ Carlos R. Bueno Júnior \\ Marcele A. Coelho \\ Katt C. Mattos \\ Patricia C. Brum
}

Escola de Educação Física e Esporte, Universidade de São Paulo, São Paulo, SP.

Endereço para correspondência: Patricia Chakur Brum

Laboratório de Fisiologia Celular e Molecular do Exercício. Escola de Educação Física e Esporte-USP Av. Prof. Mello Moraes, 65 05508-030 - São Paulo, SP - Brasil

E-mail: pcbrum@usp.br

Este estudo foi financiado pelo Projeto Jovem Pesquisador Fapesp (02/04588-8). A aluna T.F.C foi bolsista da Fapesp (03/07548-0). P.C.B. tem bolsa produtividade em pesquisa do $\mathrm{CNPq}(\mathrm{BPq})$.

Submetido em 06/08/2008 Versão final recebida em 05/12/2008 Aceito em 29/01/2009

\section{RESUMO}

O aumento da atividade nervosa simpática e a taquicardia em repouso ou durante esforços físicos estão associados ao aumento da morbimortalidade, mesmo na ausência de sinais clínicos de doença cardíaca. Sabendo-se da importância dos receptores $\alpha_{2 A} / \alpha_{2 c}$-adrenérgicos na modulação da atividade nervosa e frequência cardíaca ( $F C)$, o presente trabalho utiliza um modelo genético de cardiomiopatia induzida por excesso de catecolaminas circulantes baseado na inativação gênica dos receptores $\alpha_{2 A} / \alpha_{2 c}$-adrenérgicos em camundongos $\left(\alpha_{2 \mathrm{~A}} / \alpha_{2 C} \mathrm{KO}\right)$ para verificar a resposta da FC ao exercício físico (EF), assim como o controle simpatovagal da FC ao EF. Testou-se a hipótese de que haveria resposta taquicárdica exacerbada durante o EF nos camundongos $\alpha_{2 \AA} / \alpha_{2} \mathrm{KO}$ mesmo quando a função cardíaca ainda estivesse preservada em repouso, sendo o receptor $\alpha_{2 A}$-adrenérgico o principal responsável por essa resposta. Camundongos machos da linhagem C57Bl6J, controle (CO) e com inativação gênica para os receptores $\left.\alpha_{2 \mathrm{~A}}\left(\alpha_{2 \mathrm{~A}} \mathrm{KO}\right), \alpha_{2 C} \alpha_{2 \mathrm{C}} \mathrm{KO}\right)$ e $\alpha_{2 \mathrm{~A}} / \alpha_{2 C} \mathrm{KO}$ foram submetidos a um teste de tolerância ao esforço físico. Outros dois grupos de camundongos, $\mathrm{CO}$ e $\alpha_{2 \AA} / \alpha_{2} \mathrm{KO}$, foram submetidos ao bloqueio farmacológico dos receptores muscarínicos e $\beta$-adrenérgicos e ao EF progressivo para se avaliar a contribuição simpatovagal para a taquicardia de EF. Observou-se intolerância ao esforço físico (1.220 \pm 18 e $1.460 \pm 34$ vs. $2.630 \pm 42 \mathrm{~m}$, respectivamente) e maior taquicardia ao EF (765 \pm 16 e $792 \pm$ 13 vs. $603 \pm 18 \mathrm{bpm}$, respectivamente) nos camundongos $\alpha_{2 A} \mathrm{KO}$ e $\alpha_{2 A} / \alpha_{2} \mathrm{KO}$ vs. CO. Além disso, o balanço autonômico estava alterado nos camundongos $\alpha_{2 \mathrm{~A}} / \alpha_{2} \mathrm{KO}$ pela hiperatividade simpática e menor efeito vagal cardíaco. Esses resultados demonstram a importância dos receptores $\alpha_{2 A} / \alpha_{2 c}$-adrenérgicos no controle autonômico não só no repouso, mas também durante o EF, sendo o receptor $\alpha_{2 A}$-adrenérgico o responsável pela hiperatividade simpática e menor efeito vagal observados. Essa resposta taquicárdica exacerbada nos camundongos $\alpha_{2 A} / \alpha_{2} \mathrm{KO}$ está presente mesmo quando ainda não se observa disfunção cardíaca.

Palavras-chave: frequência cardíaca, receptores $\alpha_{2}$-adrenérgicos, exercício físico, resposta taquicárdica, controle autonômico cardíaco.

\section{ABSTRACT}

Increase of sympathetic nervous activity and tachycardia at rest or during physical exertions are associated with increase of morbimortality, even in the absence of clinical signs of cardiac disease. Considering the importance of the $\alpha_{2 A} / \alpha_{2 c}$-adrenergic receptors in the modulation of the nervous activity and heart rate (HR), the present study uses a genetic model of cardiomyopathy induced by excess of circulating catecholamine in the gene inactivation of the $\alpha_{2 A} / \alpha_{2}$-adrenergic receptors in mice $\left(\alpha_{2 A} / \alpha_{2} \mathrm{KO}\right)$ to verify the HR response to physical exercise (PE), as well as the sympathetic-vagal control of the HR to PE. The hypothesis is that there would be exacerbated tachycardic response during PE in $\alpha_{2 A} / \alpha_{2} \mathrm{KO}$ mice even when the cardiac function was still preserved at rest, being the $\alpha_{2 A}$ - adrenergic receptor the main reason for this response. Male mice of the C57Bl6J lineage, control (CO) and with gene inactivation for the $\mathrm{a}_{2 \mathrm{~A}}\left(\alpha_{2 \mathrm{~A}} \mathrm{KO}\right), \alpha_{2 \mathrm{C}} \alpha_{2 \mathrm{KO}} \mathrm{K}$ and $\alpha_{2 \mathrm{~A}} / \alpha_{2 \mathrm{C}} \mathrm{KO}$ receptors were submitted to tolerance to a physical exercise test. Two other groups of mice, $\mathrm{CO}$ and $\alpha_{2 \mathrm{~A}} / \alpha_{2 \mathrm{C}} \mathrm{KO}$, were submitted to pharmacological blocking of the muscarinic and $\beta$-adrenergic receptors as well as to progressive $P E$ to assess the sympathetic-vagal contribution to PE tachycardia. Intolerance to physical exercise (1.220 \pm 18 and $1.460 \pm 34$ vs. $2.630 \pm 42 \mathrm{~m}$, respectively) and higher tachycardia to $P E(765 \pm 16$ e $792 \pm 13$ vs. $603 \pm 18$ bpm, respectively) in the $\alpha_{2 A} \mathrm{KO}$ and $\alpha_{2 A} / \alpha_{2 C} \mathrm{KO}$ vs. CO mice was observed. Moreover, the autonomic balance was altered in the $\alpha_{2 \mathrm{~A}} \mathrm{~A} \alpha_{2} \mathrm{KO}$ mice by the sympathetic hyperactivity and lower cardiac vagal effect. These outcomes demonstrated the importance of the $\alpha_{2 A} / \alpha_{2 C}$-adrenergic receptors in autonomic control not only at rest, but also during $P E$, being the $\alpha_{2 A}$-adrenergic receptor responsible for the sympathetic hyperactivity and lower vagal effect observed. This exacerbated tachycardic response in $\alpha_{2 \mathrm{~A}} / \alpha_{2 \mathrm{C}} \mathrm{KO}$ mice is present even when cardiac dysfunction is not observed.

Keywords: heart rate; $\alpha_{2}$-adrenergic receptors; physical exercise; tachycardic response; cardiac autonomic control. 


\section{INTRODUÇÃO}

O balanço autonômico cardíaco está alterado na insuficiência cardíaca (IC), sendo observada hiperativação do sistema nervoso simpático e redução no tônus vagal cardíaco. Na fase inicial da síndrome, a ativação do sistema nervoso simpático, assim como níveis plasmáticos elevados de renina, noradrenalina, hormônio natriurético e arginina vasopressina, representa importantes mecanismos compensatórios para a manutenção do débito cardíaco e da pressão arterial ${ }^{(1,2,3)}$; não é observada disfunção cardíaca em repouso, porém, apenas durante a realização de esforço físico. No entanto, exposições crônicas às catecolaminas liberadas pelos terminais nervosos simpáticos levam a aumento contínuo da atividade simpática que contribui para o dano miocárdico e para a deterioração da função cardíaca(4).

A inativação gênica dos receptores $\alpha_{2 A}$ e $\alpha_{2 c}$-adrenérgicos em camundongos ( $\left.\alpha_{2 A} / \alpha_{2} K O\right)$ provoca hiperatividade do sistema nervoso simpático ${ }^{(5,6,7)}$, sendo um ótimo modelo experimental, pois mimetiza as alterações fisiopatológicas características de pacientes com insuficiência cardíaca para o estudo de quadros clínicos associados à hiperatividade simpática. Essa hiperatividade ocorre devido à regulação inibitória exercida pelos receptores $\alpha_{2 A}$ e $\alpha_{2 C}$ sobre a secreção de noradrenalina pelos terminais nervosos simpáticos ${ }^{(5,6,7,8,9)}$. No entanto, os receptores $\alpha_{2 A}$ adrenérgicos exercem sua ação inibitória, quando há despolarização de alta frequência dos terminais, enquanto os receptores $\alpha_{2 c}$ adrenérgicos inibem a secreção de noradrenalina em despolarizações de baixa frequência, próximas às observadas em repouso(5) ${ }^{(5)}$ Camundongos $\alpha_{2 A} / \alpha_{2 C} K O$ apresentam concentrações plasmáticas de noradrenalina elevadas $(5,6,7,8,9)$. No entanto, aos três meses de idade, essa hiperatividade simpática não repercute em disfunção cardíaca ou remodelamento cardíaco(10), sendo observados, somente aos sete meses de idade, sinais clínicos de insuficiência cardíaca, tais como, disfunção cardíaca grave, edema pulmonar e taxa de mortalidade de $50 \%{ }^{(10)}$.

Vários autores $(5,6,7,8,9,11,12)$ demonstraram o papel dos receptores $\alpha_{2 \mathrm{~A}}$ e $\alpha_{2 C}$ adrenérgicos na regulação da liberação de noradrenalina e consequente hiperatividade simpática em situação de repouso, porém, não há na literatura nenhum estudo que verifique a função desses receptores quando o organismo é submetido a algum estresse que altere sua FC e o balanço autonômico.

Como esses camundongos com hiperatividade simpática, descritos acima, ainda não apresentam disfunção miocárdica aos três meses de idade e o eletrocardiograma de esforço é um teste mais sensível para detecção de doença cardíaca mesmo quando a função cardíaca está preservada em repouso ${ }^{(13,14)}$, o presente estudo teve como objetivos: verificar o comportamento da FC durante o teste de tolerância ao esforço físico nos camundongos $\mathrm{CO}, \alpha_{2 \mathrm{~A}} \mathrm{KO}, \alpha_{2} \mathrm{KO}$ e $\alpha_{2 A} / \alpha_{2 C} K O$ aos três meses de idade, quando a cardiomiopatia está em estágio inicial e com função cardíaca preservada; e avaliar a contribuição do sistema nervoso simpático e parassimpático sobre a resposta taquicárdica ao exercício físico nos camundongos $\alpha_{2 \mathrm{~A}} / \alpha_{2 \mathrm{C}} \mathrm{KO}$ e CO, por meio de bloqueio farmacológico de receptores muscarínicos e $\beta$-adrenérgicos.

\section{MÉTODOS}

\section{Amostra}

A amostra foi composta por camundongos machos (C57BL/6J) com 12 semanas de idade, distribuídos em dois protocolos experimentais distintos:

- Protocolo 1: 32 camundongos, sendo oito $\mathrm{CO}$, oito $\alpha_{2 \mathrm{~A}} / \alpha_{2 \mathrm{C}} \mathrm{KO}$, oito $\alpha_{2 \mathrm{~A}} \mathrm{KO}$ e oito $\alpha_{2 \mathrm{C}} \mathrm{KO}$;

- Protocolo 2: 31 camundongos, sendo $15 \mathrm{CO}$ e $16 \alpha_{2 \mathrm{~A}} / \alpha_{2 \mathrm{CO}} \mathrm{KO}$
Os camundongos foram mantidos em gaiolas com temperatura controlada entre 22 e $25^{\circ} \mathrm{C}$, ciclo claro-escuro (12 horas) invertido e ração e água ad libitum. Todos os procedimentos adotados seguiram as recomendações do Colégio Brasileiro de Experimentação Animal (www. cobea.org.br) e foram aprovados pelo Comitê de Ética da Escola de Educação Física e Esporte da Universidade de São Paulo (CEP \# 004).

\section{Genotipagem}

Os camundongos $\alpha_{2 \mathrm{~A}} \mathrm{KO}, \alpha_{2 \mathrm{C}} \mathrm{KO}$ e $\alpha_{2 \mathrm{~A}} / \alpha_{2 \mathrm{C}} \mathrm{KO}$ foram genotipados a partir da extração de DNA genômico por meio de biopsia realizada na orelha esquerda dos animais. A genotipagem foi realizada por meio da reação em cadeia da polimerase (PCR-polymerase chain reaction) com termociclador utilizando oligonucleotídeos iniciadores (primers) para a detecção dos genes intactos e com ruptura dos genes dos receptores $\alpha_{2 A}$ e $\alpha_{2 C^{-}}$adrenérgicos ${ }^{(11)}$.

\section{Eletrocardiograma durante o teste de tolerância aos esforços físicos}

Para possibilitar o monitoramento da FC, foram implantados três eletrodos de aço inoxidável nas regiões torácica direita, esquerda e dorsal, com fixação das extremidades externas junto à cabeça dos camundongos $\alpha_{2 \mathrm{~A}} \mathrm{KO}, \alpha_{2 \mathrm{CO}} \mathrm{KO} \alpha_{2 \mathrm{~A}} / \alpha_{2 \mathrm{C}} \mathrm{KO}$ e CO anestesiados com ketamina $(80 \mathrm{mg} / \mathrm{kg})$ e xilasina $(12 \mathrm{mg} / \mathrm{kg})$.

Durante o teste de tolerância ao esforço físico foi realizado o registro do eletrocardiograma dos camundongos. O sinal do eletrocardiograma foi amplificado por um bioelétrico (Hewlett-Packard) e posteriormente registrado em microcomputador em tempo real (AT/CODAS $1000 \mathrm{~Hz}$ ).

\section{Protocolo 1. Resposta taquicárdica durante o teste de tolerância ao esforço físico}

O teste de tolerância ao esforço físico foi realizado em camundongos $\mathrm{CO}, \alpha_{2 \mathrm{~A}} / \alpha_{2 \mathrm{C}} \mathrm{KO}, \alpha_{2 \mathrm{~A}} \mathrm{KO}$ e $\alpha_{2 \mathrm{C}} \mathrm{KO}$ aos três meses de idade em esteira rolante ${ }^{(8)}$, com protocolo de intensificação de EF escalonado. Após um período de 15 minutos de repouso na esteira, os camundongos foram submetidos ao EF escalonado progressivo, com incremento de carga de três metros/minuto a cada três minutos, iniciando com velocidade de seis metros/minuto, até a exaustão do animal e um período de recuperação de cinco minutos ${ }^{(15)}$.

\section{Protocolo 2. Controle autonômico da resposta taquicárdica durante o exercício físico progressivo}

Para possibilitar a administração dos fármacos para o bloqueio dos receptores muscarínicos e adrenérgicos, foi implantada uma cânula na veia jugular dos camundongos $\alpha_{2 \mathrm{~A}} / \alpha_{2 \mathrm{C}} \mathrm{KO}$ e $\mathrm{CO}$ anestesiados com ketamina $(80 \mathrm{mg} / \mathrm{kg})$ e xilasina $(12 \mathrm{mg} / \mathrm{kg})$.

Vinte e quatro horas após a execução do teste de tolerância ao esforço físico foi realizado o teste de EF progressivo em três diferentes intensidades, 30\%, 60\% e 85\% da velocidade máxima obtida no teste realizado no dia anterior, com duração de três minutos em cada carga; a FC dos camundongos foi registrada sob bloqueio farmacológico dos receptores muscarínicos cardíacos com metilatropina $(1 \mathrm{mg} / \mathrm{kg}$, i.v.). Após o término do EF, propranolol foi injetado (3mg/kg, i.v.) e, 15 minutos após, o EF foi repetido. Esse último experimento foi realizado visando obter a FC intrínseca durante o EF progressivo.

No dia seguinte, o mesmo experimento com bloqueio farmacológico foi realizado em ordem inversa, ou seja, primeiro houve a administração de propranolol.

O cálculo dos efeitos vagal e simpático durante o EF foi realizado

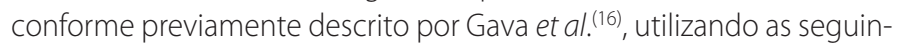
tes fórmulas:

Efeito vagal $=$ FC pós-bloqueio com metilatropina - FC da sessão controle 
Efeito simpático $=$ FC da sessão controle - FC pós-bloqueio com propranolol.

O comportamento da FC intrínseca durante o EF foi calculado pela resposta da FC após bloqueio duplo com metilatropina e propranolol.

O desenho experimental do estudo pode ser observado na figura 1.

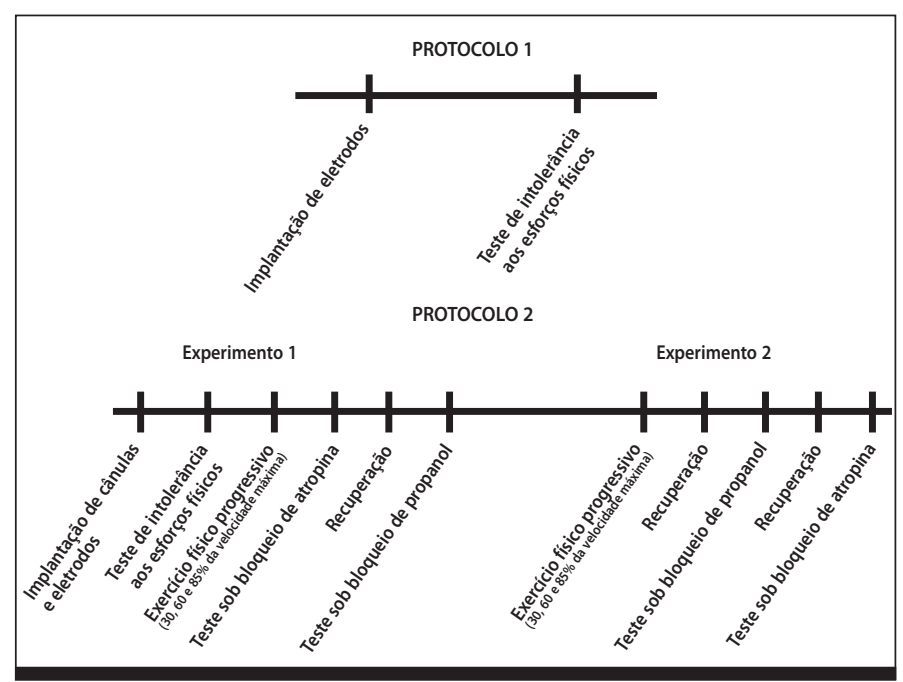

Figura 1. O estudo é composto pelo protocolo experimental 1 (resposta taquicárdica durante o teste de intolerância aos esforços físicos) e pelo protocolo experimental 2 (controle autonômico da resposta taquicárdica durante o exercício físico progressivo).

\section{Análise estatística}

Os resultados são apresentados na forma de média \pm erro padrão da média. A resposta taquicárdica ao EF e os efeitos simpático e vagal durante o EF foram comparados entre os grupos por meio de análise de variância de um fator (genótipo) para medidas repetidas. Para os casos de significância foi utilizado o teste post-hoc de Tukey. Utilizamos estatística paramétrica após aplicação de teste de normalidade (teste de Kolmogorov-Smirnov) e de homocedasticidade (teste de Bartlett. Os resultados foram considerados estatisticamente significantes quando $p<0,05$.

\section{RESULTADOS} físico.

Resposta taquicárdica durante o teste de tolerância ao esforço

Os camundongos $\alpha_{2 \mathrm{~A}} \mathrm{KO}, \alpha_{2} \mathrm{KO}, \alpha_{2 \mathrm{~A}} / \alpha_{2} \mathrm{KO}$ e CO foram submetidos ao teste de tolerância ao esforço físico com protocolo de intensificação de EF escalonado. Os camundongos $\alpha_{2 \mathrm{~A}} \mathrm{KO}$ e $\alpha_{2 \mathrm{~A}} / \alpha_{2 \mathrm{~K}} \mathrm{KO}$ percorreram distâncias significantemente inferiores à percorrida pelos camundongos CO de mesma faixa etária (figura 2A), apresentando nítida intolerância à realização de esforços. Quando comparamos a resposta taquicárdica, verificamos que os camundongos $\alpha_{2 \mathrm{~A}} \mathrm{KO}$ e $\alpha_{2 \mathrm{~A}} / \alpha_{2 \mathrm{C}} \mathrm{KO}$ apresentaram maior elevação da FC com o incremento de carga durante o teste que os camundongos $\mathrm{CO}$ (figura 2B).

Controle autonômico da resposta taquicárdica durante o exercício físico progressivo.

$\mathrm{Na}$ figura 3 observa-se que a FC durante o EF progressivo apresentou valores absolutos superiores nos camundongos $\alpha_{2 A} / \alpha_{2 C} \mathrm{KO}$ quando comparados com os camundongos CO (30\%, $680 \pm 23,1$ vs. $647 \pm 23,3 \mathrm{bpm} ; 60 \%, 721 \pm 13$ vs. $684 \pm 20 \mathrm{bpm} ; 85 \%, 741 \pm 8,8$ vs. $706 \pm$ 19,6bpm), corroborando os dados prévios desses grupos apresentados na figura 2B. Essa resposta estava associada ao menor efeito vagal nos camundongos $\alpha_{2 \mathrm{~A}} / \alpha_{2} \mathrm{KO}$ em relação aos camundongos $\mathrm{CO}(30 \%, 61,6$ $\pm 29,1$ vs. $76,3 \pm 20,1 \mathrm{bpm} ; 60 \%, 31,8 \pm 17,3$ vs. $55,5 \pm 13,2 \mathrm{bpm} ; 85 \%$, $19,8 \pm 21$ vs. $27,6 \pm 15,1 \mathrm{bpm})$, uma vez que o efeito simpático não foi diferente entre os grupos (figura 4).
A

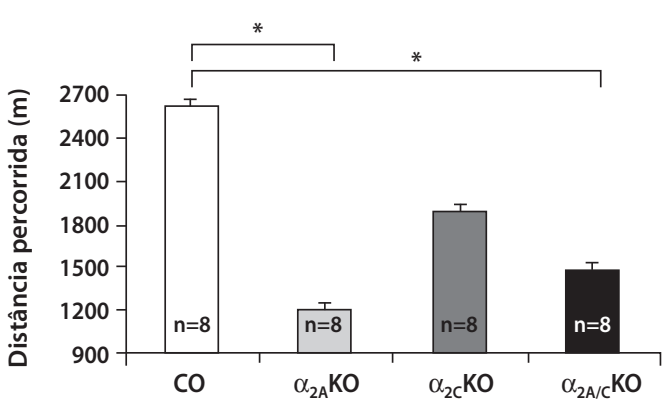

B

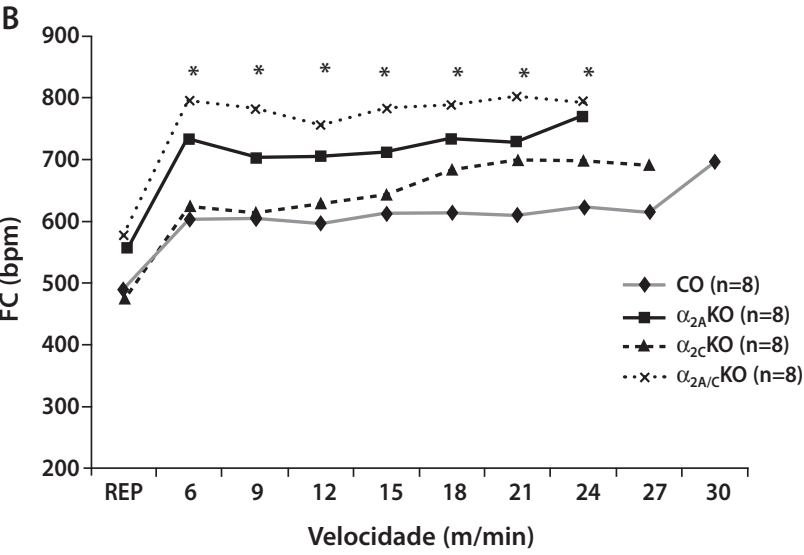

Figura 2. Distância máxima percorrida (painel A) e frequência cardíaca (painel B) observada em teste de tolerância aos esforços em camundongos controle (CO) e com inativação gênica dos receptores $\alpha_{2 \mathrm{~A}}\left(\alpha_{2 \mathrm{~A}} \mathrm{KO}\right), \alpha_{2 C}\left(\alpha_{2 \mathrm{C}} \mathrm{KO}\right)$ e $\alpha_{2 \mathrm{~A}}$ e $\alpha_{2 c}$-adrenérgicos $\left(\alpha_{2 A} / \alpha_{2} K O\right), n=8$ para cada grupo. Rep.: repouso.

${ }^{*} \mathrm{p}<0,05 \alpha_{22} / \alpha_{2} \mathrm{KO}$ e $\alpha_{24} \mathrm{KO}$ vs. CO

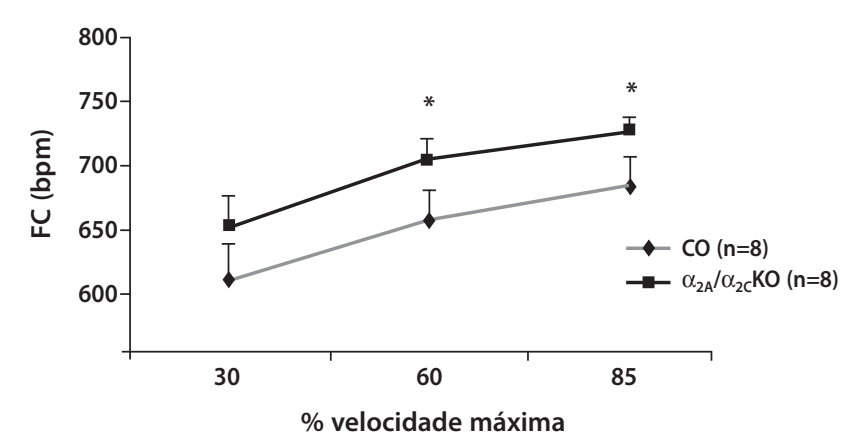

Figura 3. Resposta taquicárdica ao exercício físico progressivo realizado a 30, 60 e 85\% da velocidade máxima atingida no teste até a exaustão em camundongos controle (CO) e com inativação gênica dos receptores $\alpha_{2 A}$ e $\alpha_{2 c}$-adrenérgicos $\left(\alpha_{2 A} / \alpha_{2 C} \mathrm{KO}\right)$. $\mathrm{n}=8$ para cada grupo.

${ }^{*} \mathrm{p}<0,05 \alpha_{22} / \mathrm{KO}$ v. $\mathrm{CO}$.

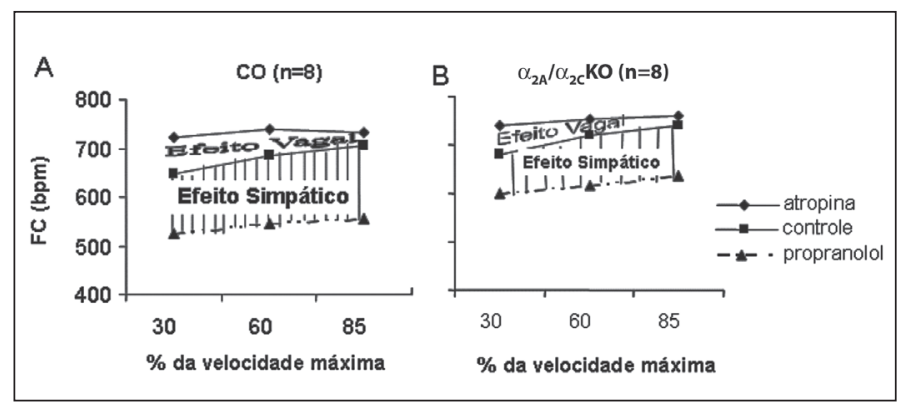

Figura 4. Efeito vagal (atropina-controle) e simpático (propranolol-controle) sobre a FC durante o exercício físico realizado a 30, 60 e 85\% da velocidade máxima atingida no teste até a exaustão (camundongos controle (CO) e com inativação gênica dos receptores $\alpha_{2 \mathrm{~A}}$ e $\alpha_{2 C}$-adrenérgicos $\left(\alpha_{2 \mathrm{~A}} / \alpha_{2 \mathrm{C}} \mathrm{KO}\right)$ ). $\mathrm{n}=8$ para cada grupo. 


\section{DISCUSSÃO}

Os receptores $\alpha_{2}$-adrenérgicos regulam a atividade do sistema nervoso simpático, sendo os receptores $\alpha_{2 A}$ e $\alpha_{2 C}$-adrenérgicos os responsáveis pelo controle da liberação de noradrenalina nos terminais nervosos simpáticos e no tecido cardíaco ${ }^{(11,12)}$.

Neste estudo, os camundongos $\alpha_{2 \mathrm{~A}} \mathrm{KO}$ e $\alpha_{2 \mathrm{~A}} / \alpha_{2 \mathrm{~K}} \mathrm{KO}$ apresentaram intolerância à realização de esforço físico e maior resposta da FC durante o teste de tolerância ao esforço físico quando comparados com os camundongos $\alpha_{2}$ KO e CO. Isso pode ter ocorrido devido ao maior controle inibitório sobre a secreção de noradrenalina apresentado pelos receptores $\alpha_{2 A}$-adrenérgicos ${ }^{(8,9,12)}$. Em camundongos com inativação gênica para os receptores $\alpha_{2 A}$-adrenérgicos, há aumento na atividade simpática com taquicardia de repouso ${ }^{(17)}$, o que não ocorre com aqueles que têm os receptores $\alpha_{2 c}$ adrenérgicos inativados ${ }^{(18)}$.

Essa resposta taquicárdica durante o esforço deve estar relacionada com hiperatividade simpática nos camundongos $\alpha_{2 \mathrm{~A}} \mathrm{KO}$ e $\alpha_{2 \mathrm{~A}} / \alpha_{2 \mathrm{C}} \mathrm{KO}$, que é acompanhada de intolerância à realização de esforço. Em camundongos $\alpha_{2 \mathrm{~A}} / \alpha_{2} \mathrm{KO}$ já observamos intolerância aos esforços, que se agrava com a progressão da doença ${ }^{(15)}$ e associa-se tanto a disfunção cardíaca ${ }^{(10,19)}$ quanto a alterações na função e na estrutura da musculatura esquelética ${ }^{(20)}$.

Em relação ao balanço autonômico durante o EF progressivo, observou-se que a resposta da FC foi maior nos camundongos $\alpha_{2 \mathrm{~A}} / \alpha_{2 \mathrm{C}} \mathrm{KO}$ em comparação com os camundongos $C O$. Essa resposta está associada a menor efeito vagal, já que o tônus basal simpático nos camundongos $\alpha_{2 \mathrm{~A}} / \alpha_{2 \mathrm{~K}} \mathrm{KO}$ é mais alto, o que acarreta menor reserva simpática para elevação da FC durante o EF nos camundongos $\alpha_{2 \mathrm{~A}} / \alpha_{2 \mathrm{C}} \mathrm{KO}$ em relação aos $\mathrm{CO}$.

A hiperatividade simpática tem um papel importante na fisiopatologia e evolução da doença cardiovascular(21). Nos camundongos $\alpha_{2 \mathrm{~A}} / \alpha_{2 \mathrm{~K}} \mathrm{KO}$, os níveis plasmáticos elevados de catecolaminas fazem com que o coração se adapte inicialmente, causando um remodelamento cardíaco com hipertrofia e aumento da FC. Contudo, há uma falha no mecanismo compensatório com o avançar da idade nesses camundongos $^{(10)}$, acarretando insuficiência cardíaca grave e 50\% de mortalidade aos sete meses de idade ${ }^{(19)}$. Portanto, os resultados do presente estudo demonstram, pela primeira vez, a importância dos receptores $\alpha_{2 A} / \alpha_{2 C}$-adrenérgicos no controle autonômico, não só no repouso, mas também durante o EF, sendo o receptor $\alpha_{2 A}$-adrenérgico o responsável pela hiperatividade simpática e menor efeito vagal observados. Além disso, alterações na resposta taquicárdica, mesmo na ausência de disfunção cardíaca, sugerem que a FC possa ser utilizada como ferramenta prognóstica.

Trabalhos do nosso grupo também corroboram a hipótese de que o treinamento físico aeróbico constitui-se em uma estratégia não farmacológica que reduz a FC e melhora o balanço autonômico em camundongos com insuficiência cardíaca durante o $\mathrm{EF}^{(10,19)}$. Dessa forma, o exercício físico regular seria altamente recomendado para minimizar os efeitos deletérios da hiperatividade simpática presentes nas doenças cardiovasculares e fatores de risco.

Apesar de os nossos dados apresentarem como limitação o fato de os camundongos terem realizado os protocolos experimentais com eletrodos subcutâneos implantados, acreditamos que isso não tenha interferido de maneira importante no seu desempenho físico durante o esforço, pois os resultados desses testes não foram diferentes dos realizados sem a presença dos eletrodos.

\section{CONSIDERAÇÕES FINAIS}

Nossos dados mostraram intolerância aos esforços físicos e taquicardia exacerbada nos camundongos $\alpha_{2 \mathrm{~A}} \mathrm{KO}$ e $\alpha_{2 \mathrm{~A}} / \alpha_{2 C} \mathrm{KO}$ em relação aos CO. Além disso, verificou-se balanço autonômico alterado nos camundongos $\alpha_{2 A} / \alpha_{2 C} K O$ durante o exercício físico progressivo com menor efeito vagal, evidenciando a hiperatividade do sistema nervoso simpático e a importância desses receptores no controle da FC e do balanço autonômico. tanto em repouso quanto em exercício físico.

Todos os autores declararam não haver qualquer potencial conflito de interesses referente a este artigo.

\section{REFERÊNCIAS BIBLIOGRÁFICAS}

1. Bristow MR. The adrenergic nervous system in heart failure. New Engl J Med 1984; 311:850-851.

2. Colucci WS, Sawyer DB, Singh K, Communal C. Adrenergic overload and apoptosis in heart failure: implications for therapy. J Card Fail 2000; 6:1-17.

3. Franchini K. Função e disfunção autonômica na doença cardiovascular. Rev SOCESP 1998; 8:285-297.

4. Cicogna ACO, MP, Okoshi K. História natural da remodelação miocárdica: da agressão aos sintomas. Rev SOCESP 2000; 10:8-16.

5. Hein L, Altman JD, Kobilka BK. Two functionally distinct alpha 2-adrenergic receptors regulate sympathetic neurotransmission. Nature 1999; 402: 181-184.

6. Philipp M, Brede M, Hein L. Physiological significance of alpha2-adrenergic receptor subtype diversity: one receptor is not enough. Am J Physiol-Reg I 2002; 283:287-295.

7. Brede M, Nagy G, Philipp M, Sorensen JB, Lohse MJ, Hein L. Differential control of adrenal and sympathetic catecholamine release by alpha2-adrenoceptor subtypes. Mol Endocrinol 2003; 17(8):1640-6.

8. Knaus AN, Muthig V, Schickinger S, Moura E, Beetz N, Gilsbach R, Hein L. a2-Adrenoceptor subtypes - Unexpected functions for receptors and ligands derived from gene-targeted mouse models. Neurochem Int 2007, 51: 277-281.

9. Brede M, Philipp M, Knaus A, Muthig V, Hein L. Alpha2-adrenergic receptor subtypes - novel functions uncovered in gene-targeted mouse models. Biol Cell 96 2004, 343-348.

10. Medeiros A, Rolim NPL, Oliveira RSF, Rosa KT, Mattos KC, Casarini DE, Irigoyen MC, Krieger EM, Krieger JE, Negrão CE, Brum PC. Exercise training delays cardiac dysfunction and prevents calcium handling abnormalities in sympathetic hyperactivity-induced heart failure mice. J Appl Physiol 2008; 104:103-9.

11. Brum PC, Kosek J, Patterson A, Bernstein D, Kobilka B. Abnormal cardiac function associated with sympathetic nervous system hyperactivity in mice. Am J Physiol 2002; 283:1838-1845.

12. Brum PC, Hurt CM, Shcherbakova OG, Kobilka B, Angelotti T. Differential targeting and function of a2A and a2C adrenergic receptor subtypes in cultured sympathetic neurons. Neuropharmacology 2006; 51:399-413.
13. Beniaminovitz A, Mancini DM. The role of exercise-based prognosticating algorithms in the selection of patients for heart transplantation. Curr Opin Cardiol 1999; 14:114-120.

14. Mancini DR, Goldsmith H, Levin A, Beniaminovitz E, Rose K, Catanese M, Oz M. Comparison of exercise performance in patients with chronic severe heart failure versus left ventricular assist devices. Circulation 1998; 1178-1783.

15. Ferreira JC, Bacurau AVN, Evangelista FS, Coelho MA, Oliveira EM, Casarini DE, Krieger JE, Brum PC. The role of local and systemic renin angiotensin system activation in a genetic model of sympathetic hyperactivity-induced heart failure in mice. Am J Physiol 2008; 294:26-32.

16. Gava NS, Veras-Silva AS, Negrão CE, Krieger EM. Low-intensity exercise training attenuates cardiac beta-adrenergic tone during exercise in spontaneously hypertensive rats. Hypertension 1995; 26:1129-1133.

17. Altman JD, Trendelenburg AU, Macmillan L, Berstein D, Limbird L, Starke K, Kobilka BK, Hein L. Abnormal regulation of the sympathetic nervous system in $\alpha_{2}$-adrenergic receptor knockout mice. Mol Pharmacol 1999; 56:154-161

18. Link R, Desai H, Hein L, Stevens ME, Chruskinski A, Bernstein D, Barsh GS, Kobilka BK. Cardiovascular regulation in mice lacking $a_{2}$-adrenergic receptor subtypes b and c. Science 1996; 273:803-805.

19. Rolim, NPL, Medeiros A, Rosa KT, Mattos KC, Irigoyen MC Krieger EM, Krieger JE, Negrão CE, Brum PC. Exercise training improves the net balance of cardiac $\mathrm{Ca} 2+$ handling protein expression in heart failure. Physiol Genomics 2007; 29:246-52.

20. Bacurau, AVN, Bechara L, Jardim M, Tanaka LY, Oliveira RFS, Alba-Loureiro T, Negrão CE, Curil R, Ramires PR, Brum PC. Exercise training reverses skeletal muscle atrophy and improves redox balance in a genetic model sympathetic hyperactivity-induced heart failure. In: European Society of Cardiology, Vienna. Eur Heart J 2007; 28:399-399, 2007.

21. Curtis $\mathrm{BM}, \mathrm{O}$ 'Keefe $\mathrm{JHJ}$. Autonomic tone as a cardiovascular risk factor: the dangers of chronic fight or flight. Mayo Clinic Proc; 77:45-54, 2002. 